\title{
IDENTIFICAÇÃO DA PREVALÊNCIA DE BACTÉRIAS GRAM NEGATIVAS EM ESTETOSCÓPIOS E A PRÁTICA DA HIGIENIZAÇÃO POR PROFISSIONAIS DA SAÚDE EM UM HOSPITAL DO OESTE PAULISTA
}

\author{
IDENTIFICATION OF THE PREVALENCE OF NEGATIVE GRAM BACTERIA IN STETHOS- \\ COPES AND THE PRACTICE OF HYGIENIZATION BY HEALTH PROFESSIONALS IN A \\ HOSPITAL OF OESTE PAULISTA \\ Matheus Henrique de Souza Coradini ${ }^{\mathrm{a}^{*}}$, Nelson Pereira dos Santos Neto ${ }^{\mathrm{b}^{*}}$, Larissa Gasquez \\ Magnesis $^{\mathrm{c}^{*}}$, Carolina Ferreira de Melo ${ }^{\mathrm{d}^{*}}$, Mércia de Carvalho Almeida ${ }^{\mathrm{e}^{*}}$, Sueli Cristina \\ Schadeck Zago ${ }^{{ }^{*}}$ \\ matheus-medicinapp@hotmail.com ${ }^{\mathrm{a}}$, nelsonnetop@gmail.com ${ }^{\mathrm{b}}$, lagasquez@hotmail.com ${ }^{\mathrm{c}}$, carolinaferreirademelo@hotmail.com ${ }^{\mathrm{d}}$, mercia@unoeste. \\ bre, sueli@unoeste.br ${ }^{\mathrm{f}}$ \\ Universidade do Oeste Paulista (UNIOESTE)
}

Data de recebimento do artigo: 29/10/2018

\section{RESUMO}

Data de aceite do artigo: 24/04/2019

\begin{abstract}
Os serviços de saúde, particularmente o ambiente hospitalar, apresentam um ambiente com potencial risco de contaminação, por bactérias Gram-negativas. A transmissão dessas bactérias pode ser adquirida através do ar, gotículas e principalmente por contato no qual se inclui o estetoscópio e o manejo das mãos. O estudo tem por objetivo identificar a prevalência de microrganismos Gram negativos encontrados nos diafragmas dos estetoscópios de um hospital escola de Presidente Prudente. Além disto, analisar as variáveis contidas no questionário que foi aplicado sobre higienização das mãos e dos estetoscópios. Trata-se de um estudo transversal analítico descritivo que avaliou quantitativamente em 150 estetoscópios a prevalência de microrganismos Gram negativos em um Hospital Escola de Presidente Prudente e quantitativa e qualitativamente o conhecimento de 200 profissionais da saúde e acadêmicos deste hospital sobre a prática de limpeza e desinfecção das mãos e dos estetoscópios. Foram observadas 21 amostras com microrganismos Gram negativos. Além disso, registramos através do questionário uma higienização ineficaz das mãos e dos estetoscópios com déficit principalmente na orientação de tal prática. O estudo conclui que a prevalência de microrganismos Gram negativos nas amostras analisadas é baixa, 14\%, no entanto, recomenda-se adoção de medidas mais severas para a formação dos acadêmicos e na prática dos profissionais com relação a higienização das mãos e dos estetoscópios.
\end{abstract}

Palavras-chaves: Estetoscópio, desinfecção das mãos, bactérias gram-negativas

\section{ABSTRACT}

Health services, particularly the hospital environment, present an environment with potential risk of contamination by Gram-negative bacteria. The transmission of these bacteria can be acquired through the air, droplets and mainly by contact that includes the stethoscope and the handling of the hands. The study aims to identify the prevalence of Gram negative microorganisms found in the diaphragms of stethoscopes of a school hospital in Presidente Prudente. In addition, to analyze the variables contained in the questionnaire that was applied on hand hygiene and stethoscopes. This is a cross-sectional analytical descriptive study that quantitatively evaluated 150 stethoscopes the prevalence of Gram negative microorganisms in a Hospital School of Presidente Prudente and quantitatively and qualitatively the knowledge of 200 health professionals and academics of this hospital on the practice of cleaning and disinfection hands and stethoscopes. Twenty-one samples with Gram negative microorganisms were observed. In addition, we verified through the questionnaire an inefficient hygiene of the hands and stethoscopes with deficits mainly in the orientation of such practice. The study concludes that the prevalence of Gram negative microorganisms in the analyzed samples is low, $14 \%$, however, it is recommended to adopt more severe measures for the training of academics and in the practice of professionals regarding hand hygiene and stethoscopes.

Keywords: Stethoscope, disinfection of hands, gram-negative bacteria 


\section{Introdução}

Os serviços de saúde, particularmente o ambiente hospitalar, apresentam um ambiente com potencial risco de contaminação, por bactérias Gram-negativas, uma vez que esses microrganismos são encontrados com alta frequência nesse ambiente ${ }^{1-2}$. A transmissão dessas bactérias pode ser adquirida através de três maneiras diferentes: pelo ar, por gotículas e principalmente por contato no qual se inclui o estetoscópio, pelo seu uso universal, e o manejo das mãos, visto que ainda hoje muitos médicos não lavam as mãos regularmente $e^{3-5}$.

O estetoscópio é um dos instrumentos mais utilizados no atendimento de saúde por médico e enfermeiros. Entretanto, os cuidados básicos que se refere à desinfecção e limpeza do mesmo têm sido muito negligenciados, o que torna necessário uma maior educação e adesão dos profissionais a esta prática $^{6-7}$. A literatura evidencia a classe médica como a que mais necessita de treinamento na adesão de prática que visam reduzir infecções, pois identificou que tais profissionais conhecem as medidas de prevenção, como a limpeza e desinfecção dos estetoscópios, porém as ignoram ${ }^{8}$.

A literatura relata um estudo no qual médicos auscultaram pacientes colonizados com bactérias resistentes à meticilina com estetoscópios préesterelizados, demonstrando que as pontas dos dedos dos examinadores e os diafragmas dos seus estetoscópios adquiriram contaminação durante $76 \%$ dos exames. Eles encontraram também uma forte relação entre o número de bactérias nas mãos dos examinadores e o nível quantitativo de contaminação dos estetoscópios com cada exame, trazendo assim, o estetoscópio como um possível vetor na transmissão de microrganismos .

A identificação de possíveis vias de transmissão com a finalidade de prevenir a disseminação de microrganismos causadores de infecções nos estabelecimentos de saúde é uma importante estratégia para o controle das infecções hospitalares ${ }^{10-11}$. Portanto, sabendose da possibilidade das superfícies ambientais e instrumentos contaminados terem um papel de destaque na cadeia de transmissão dos microrganismos, o rigor nos procedimentos de limpeza e desinfecção é necessário para minimizar a incidência de colonização ou infecção $0^{12-13}$.
Além da limpeza dos estetoscópios e de outros instrumentos utilizados no atendimento de saúde, a lavagem das mãos permanece como uma das intervenções mais importantes no controle de infecções nos ambientes hospitalares, pois sabe-se as mãos dos profissionais de saúde constitui um importante meio de disseminação de patógenos 14-15. Contudo, constata-se que a higienização das mãos não tem uma adesão suficiente dos profissionais, apresentando-se inferior a 50\% principalmente nos casos em que esta prática se faz necessária ${ }^{16-18}$.

Os estetoscópios analisados dos profissionais da saúde e acadêmicos do hospital escola de Presidente Prudente estão contaminados com bactérias gram-negativas, e estas não estão relacionadas ao baixo conhecimento sobre desinfecção e limpeza dos aparelhos e das mãos, mas sim com a baixa adesão dos profissionais a essas práticas.

Segundo a literatura, o diafragma dos estetoscópios e as mãos dos profissionais de saúde são vetores de infecções hospitalares. Frente a isto, averiguar o conhecimento desses profissionais para com a limpeza e desinfecção dos estetoscópios e das mãos é de suma importância para elaboração de estratégias que visam reduzir tais complicações hospitalares.

O presente estudo tem como objetivo geral verificar a prevalência de microrganismos Gram negativos encontrados nos diafragmas dos estetoscópios dos profissionais da saúde e acadêmicos de um hospital escola de Presidente Prudente. Além disto, o objetivo específico baseia-se na análise das variáveis contidas no questionário que foi aplicado, observando se há alguma significância estatística.

\section{Metodologia}

Compreende um estudo transversal analítico descritivo que avaliou quantitativamente em 150 estetoscópios a prevalência de microrganismos GRAM negativos em um Hospital Escola de Presidente Prudente (São Paulo, Brasil) e qualitativamente o conhecimento de 200 profissionais da saúde e acadêmicos deste hospital sobre a prática de limpeza e desinfecção das mãos 
e dos estetoscópios, seguindo as recomendações encontradas na literatura ${ }^{19}$. O cálculo amostral foi realizado através de uma plataforma online, na qual foi utilizado um erro amostral de 5\%, nível de confiança 95\%, uma população $(\mathrm{N})$ igual a 520 pessoas, incluindo médicos e acadêmicos, com um percentual mínimo, segundo a literatura, de $70 \%$, encontrando-se assim uma amostra de 200 pessoas $(n=200)^{1,20}$. Foi incluso na pesquisa todo profissional ou acadêmico que possui um estetoscópio e trabalhe ou estude no presente hospital, e foi excluído da pesquisa profissionais ou acadêmicos que rejeitarem participar da presente pesquisa. A coleta das 150 amostras foi realizada através de swab embebido em solução fisiológica estéril na qual foi passado no diafragma dos estetoscópios em dias aleatórios visando a não ocorrência de vieses, uma vez que ao saberem das visitas, os profissionais e acadêmicos poderão realizar a limpeza dos respectivos estetoscópios, o que atrapalharia a análise dos resultados. Após a coleta, foi aplicado, a partir da assinatura por parte do entrevistado do TCLE, um questionário modificado pelos autores (Anexo 1) a todos os participantes da pesquisa (200 participantes) que analisou qualitativamente variáveis como nível de conhecimento acerca da desinfecção dos aparelhos, grau de formação do entrevistado, ala hospitalar onde executa suas atividades, frequência e material utilizado para desinfecção'

Após a coleta, o material foi semeado em ágar sangue e levado à estufa a $37^{\circ} \mathrm{C}$ por $18-24 \mathrm{H}$, sendo corado pela coloração de Gram e identificado os microrganismos GRAM negativos existentes nas amostras através de cultivo primário logo em seguida, na qual foram utilizadas para a mesmas provas bioquímicas. Os dados foram analisados por meio de uma estatística descritiva, na qual foram tabulados e expressados através de gráficos ilustrativos, como por exemplo, gráfico percentual para visualização e intepretação da frequência de contaminação bacteriana nos aparelhos $^{21}$. Além disso, os resultados foram expressos estatisticamente em números absolutos e porcentagens, bem como a utilização do Teste Exato de Fisher, para a comparação de algumas varáveis ${ }^{21}$, trabalhando-se com níveis de significância $\alpha=5 \%{ }^{22}$.

O presente estudo foi submetido ao Comitê de Ética e Pesquisa (CEP) e aprovado pelo mesmo, recebendo o protocolo de número 2754117.5.0000.5515.

\section{Resultados}

Do total de cento e cinquenta (100\%) estetoscópios analisados, registrou-se o crescimento de vinte e uma culturas em MacConkey, correspondendo, portanto, a 14\% do total analisado. Esta baixa porcentagem de microrganismos Gram negativos encontradas no presente estudo vai de encontro aos achados na literatura.

Dos duzentos participantes entrevistados no questionário, cento e dez foram acadêmicos da área da saúde, na qual se inclui acadêmicos de medicina, de enfermagem e de fisioterapia, setenta enfermeiros, quinze médicos e cinco fisioterapeutas.

Quanto à limpeza e desinfecção do estetoscópio, cinquenta e dois acadêmicos responderam que realizam tal procedimento, correspondendo a $47,27 \%$ desses. Do total de enfermeiros, cinquenta e seis afirmaram que costumam lavar e desinfetar, correspondendo a $80 \%$. Do total de quinze médicos, onze responderam positivamente, o que é relativo a 73,33\%. Já em relação aos fisioterapeutas, quatro deles, ou seja, $80 \%$ disseram que realizam a limpeza e desinfecção dos aparelhos (Gráfico 1). A diferença do hábito de realizar a limpeza dos estetoscópios entre os profissionais da saúde (médicos, enfermeiros e fisioterapeutas) e acadêmicos da mesma área foi estatisticamente significativa, pois o valor encontrado foi $<0.00001$ $(\mathrm{p}<0,05)$, na qual os profissionais têm um hábito maior de realizar tal procedimento. 


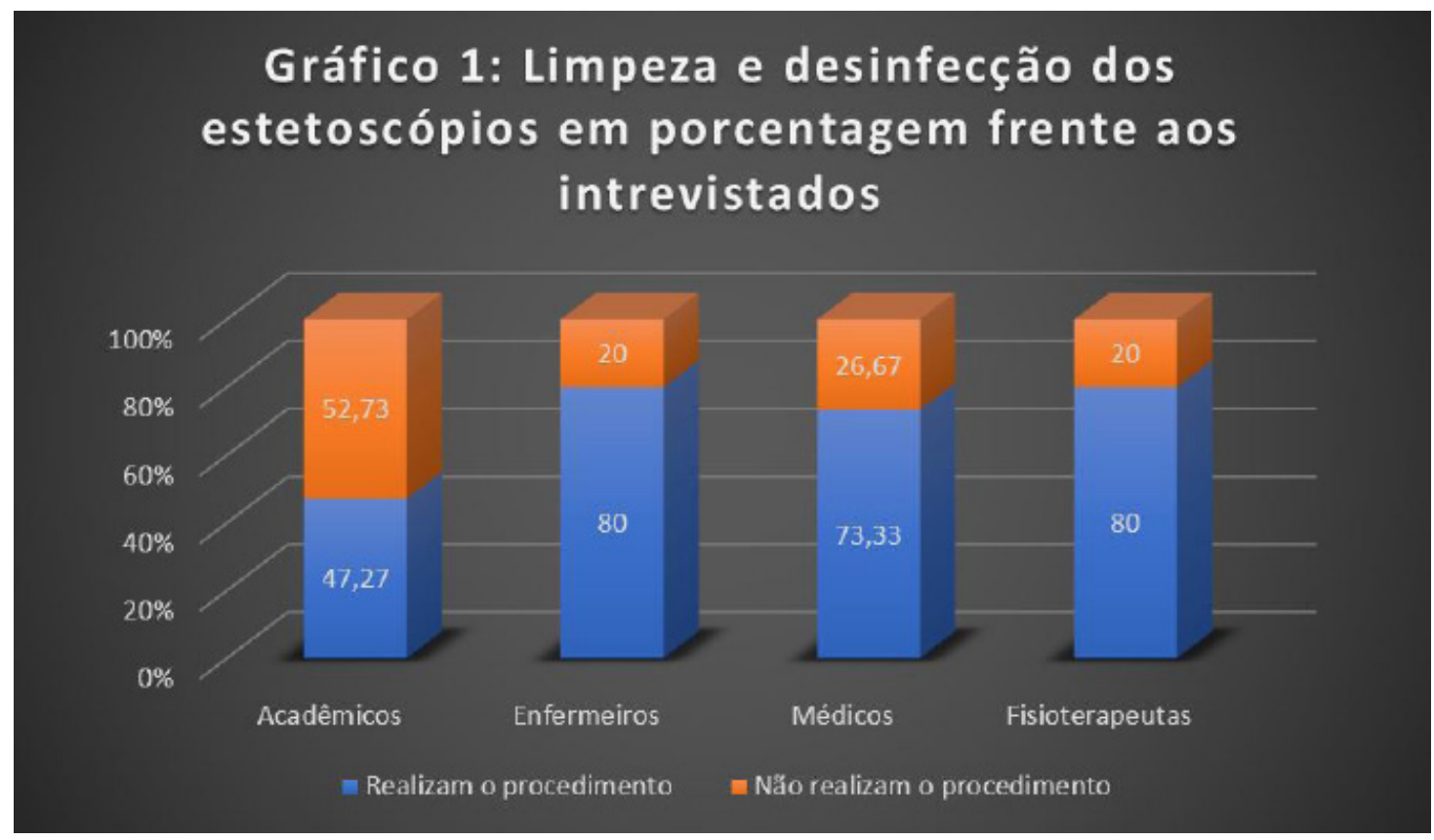

Em relação à frequência da limpeza e desinfecção do estetoscópio, verificamos que dos cento e dez acadêmicos, onze (10\%) disseram que as fazem após cada paciente, dezesseis $(14,54 \%)$ realizam diariamente, quinze $(13,63 \%)$ semanalmente, cinco (4,54\%) mensalmente e também cinco $(4,54 \%)$ disseram que quase nunca realizam, enquanto cinquenta e oito (52,75\%) afirmaram nunca ter realizado tal procedimento. No que diz respeito aos setenta da enfermagem, quarenta $(57,14 \%)$ realizam após cada paciente, doze $(17,14 \%)$ diariamente e quatro $(5,71 \%)$ semanalmente, enquanto que quatorze $(20,01 \%)$ afirmou nunca ter realizado tal procedimento. Quanto aos quinze médicos, quatro $(26,67 \%)$ afirmaram ter uma frequência diária, cinco $(33,33 \%)$ uma frequência semanal, e dois $(13,33 \%)$ mensalmente, enquanto que quatro $(26,67 \%)$, afirmaram nunca ter realizado tal procedimento. Com respeito aos cinco fisioterapeutas, verificouse que a frequência de um (20\%) profissional é após cada paciente, e, de dois (40\%), é diariamente, enquanto que dois (20\%) afirmaram nunca ter realizado tal procedimento.

Os acadêmicos responderam que costumam limpar e desinfetar seus estetoscópios com álcool e clorexidina, sendo quarenta e nove $(44,54 \%)$ com álcool e três $(2,72 \%)$ com clorexidina. A enfermagem apresentou trinta e cinco (50\%) dos profissionais entrevistados com uso de álcool e vinte e um (30\%) com clorexidina. Em relação aos médicos, seis (40\%) higienizam com álcool e cinco $(33,33 \%)$ com clorexidina. Por fim, na fisioterapia três $(60 \%)$ responderam que utilizam álcool $70 \%$.

Os entrevistados foram questionados se em alguma ocasião receberam informações ou incentivo sobre a limpeza dos estetoscópios. Dentre os acadêmicos, quarenta e cinco (40,90\%) deles responderam "sim", sessenta (54,54\%) "não" e cinco $(4,54 \%)$ "não recorda". Quanto aos enfermeiros, cinquenta e seis $(80 \%)$ afirmaram que "sim", dez (14,28\%) "não" e quatro (5,71\%) "não recordam". Em relação aos médicos, os quinze (100\%) responderam que "sim". Já entre os fisioterapeutas, obtivemos como respostas quatro (80\%) "não" e um (20\%) "não recorda". A diferença observada entre a ter tido ou não alguma orientação a respeito da limpeza do estetoscópio entre os profissionais da saúde e os acadêmicos da mesma área foi estatisticamente significativa $(\mathrm{p}<0,05)$, demonstrando que os profissionais têm uma maior orientação sobre tais procedimentos que acadêmicos.

Investigou-se também sobre a lavagem das mãos durante o expediente de trabalho. Este hábito esteve presente em $100 \%$ dos acadêmicos entrevistados bem como dos enfermeiros, médicos e fisioterapeutas. 
Ao explorar a frequência dessa lavagem das mãos durante o expediente, obtivemos como resultado que oitenta e cinco $(77,27 \%)$ dos acadêmicos a fazem após procedimentos e vinte e cinco $(22,72 \%)$ em outras ocasiões. Sessenta e oito $(97,14 \%)$ enfermeiros responderam após procedimentos e dois $(2,85 \%)$ diariamente. Em relação aos médicos, um (6,66\%) afirmou a cada dois horas, onze $(73,33 \%)$ a cada paciente e três
(20\%) realizam três vezes ao dia. E por fim, quatro (80\%) fisioterapeutas disseram antes e depois de cada paciente e um (20\%) diariamente.

Observamos que em 67,27\% (74) dos acadêmicos, 51,42\% (36) dos enfermeiros, 93,33\% (14) dos médicos e 40\% (2) dos fisioterapeutas já se esqueceram de lavar a mão alguma vez para atender a um paciente (Gráfico 2), sendo este um dado curioso e preocupante.

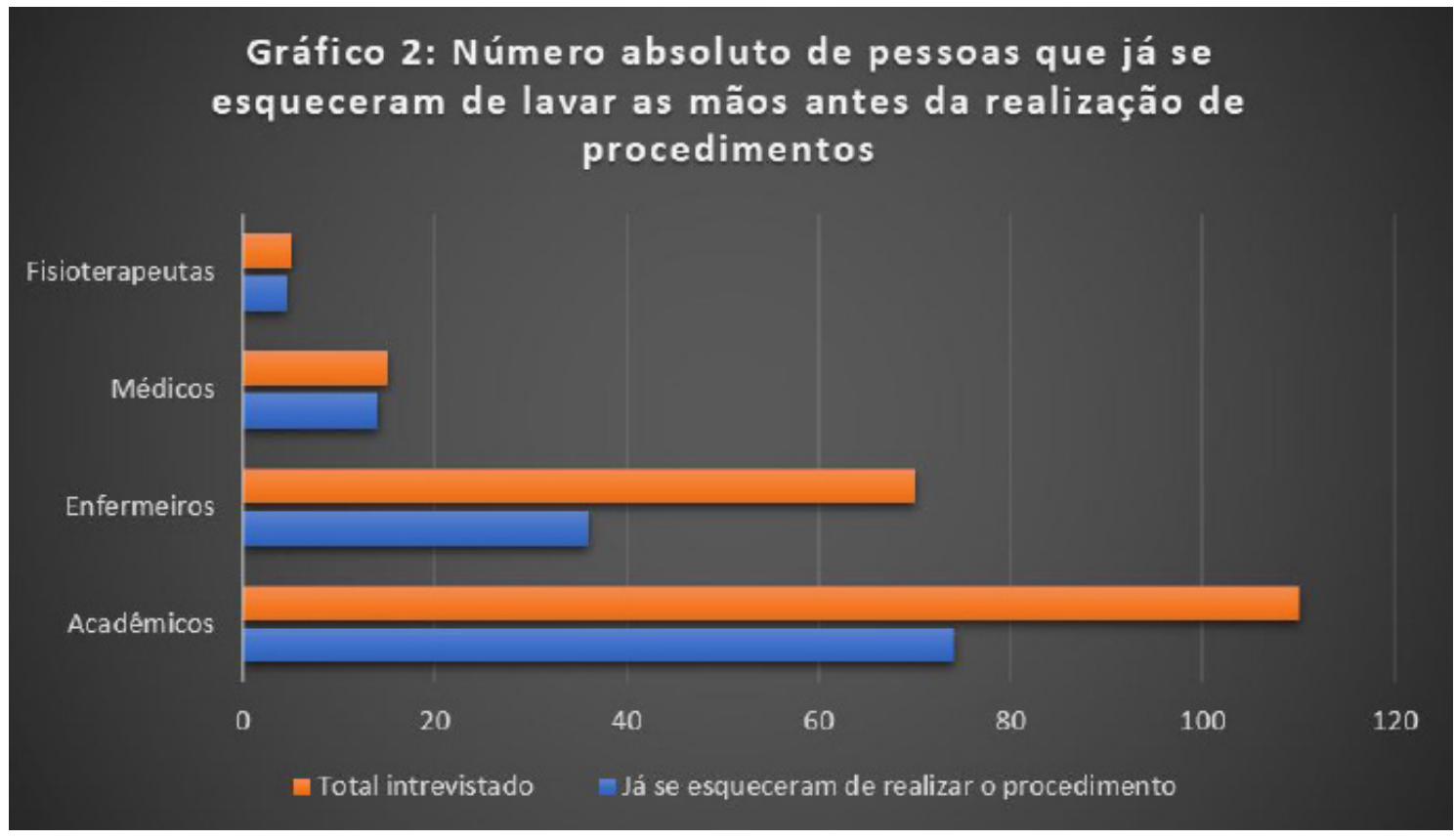

Registramos também se em alguma ocasião foram recebidas informações ou incentivo sobre a higienização das mãos. Percebeu-se que sessenta e um $(55,45 \%)$ acadêmicos responderam que "sim", quarenta e oito $(43,63 \%)$ "não" e um $(0,9 \%)$ "não recordam". Dentre os enfermeiros, foram obtidos vinte e oito (40\%) "sim". Quanto aos médicos, quatro (26,66\%) responderam "sim" e um $(6,66 \%)$ "não recorda". Por fim, entre os fisioterapeutas registrou-se três (60\%) "sim".

\section{Discussão}

Os resultados do atual estudo revelaram que 14\% do diafragma dos estetoscópios analisados estavam contaminados por bactérias Gram negativas, o que é compatível com os registros de estudos anteriores que isolaram $21 \%$ desse tipo de bactérias ${ }^{23}$. Sabe-se que as bactérias Gram negativas são encontradas principalmente do trato gastrointestinal e, portanto, entende-se que a preservação de um cuidado seguro, sem disseminação de patógenos, está diretamente relacionada à higienização das mãos pelos profissionais de saúde e pelas pessoas que transitam no setor ${ }^{11}$

A segurança é um princípio fundamental do cuidado do paciente e um componente crítico da gestão da qualidade. A sua melhoria afeta todo o sistema, pois envolve uma ampla gama de medidas para melhorar a gestão de riscos de segurança, desempenho e ambiente, ou seja, sua melhoria exige uma tarefa complexa. Dentre essas medidas a higienização das mãos é um fator primordial, no entanto, observamos uma prática inadequada da mesma segundo os índices encontrados na literatura ${ }^{24}$, nas quais estão de acordo com os achados no presente estudo. 
Essa prática é fundamental para a redução da disseminação da resistência bacteriana, lembrando que microrganismos resistentes têm a possibilidade de permanecerem nas mãos, objetos inanimados, superfícies, ambientes, assim, podem perpetuar a cadeia de transmissão. A recomendação encontrada na literatura diz que a lavagem das mãos deve ser realizada antes e após cada paciente, obedecendo a uma metodologia sistemática e sendo realizada rotineiramente com a finalidade de reduzir a disseminação deste patógeno pelo ambiente hospitalar ${ }^{24}$.

Além da frequência e metodologia aplicada na higienização das mãos, o antisséptico usado também tem sua importância na eficácia desta prática $^{24}$. Observou-se neste estudo que a maioria dos acadêmicos, enfermeiros, médicos e fisioterapeutas utilizam álcool $70 \%$ para desinfecção de equipamentos, o que é um hábito favorável segundo os achados na literatura, pois o álcool tem uma alta efetividade e o menor custo para o uso diário ${ }^{1}$.

Nota-se que a lavagem das mãos durante o expediente de trabalho é um hábito presente em $100 \%$ dos entrevistados, o que pressupõe, devido aos achados de microrganismos originários do trato gastrointestinal, que a frequência e o modo de execução da lavagem são ineficazes. Além disso, registrou-se que a metade dos profissionais da saúde e acadêmicos não receberam incentivo e/ou informações sobre a higienização das mãos. Isso pode justificar os resultados analisados no questionário sobre já ter esquecido de lavar as mãos para atender um paciente, os quais apresentaram porcentagens altas, e a presença dos microrganismos encontrados nos estetoscópios.

Importante ressaltar que independentemente do paciente estar infectado, as superfícies podem estar contaminadas. Nesse contexto, a contaminação pode estar associada com a contaminação cruzada, onde ao cuidar de pacientes em isolamento de contato e não realizar higienização das mãos, objetos e superfícies ao entorno de outros pacientes são tocadas, contaminadas e tornam-se fonte de infeção para o paciente suscetível. O baixo índice de informação dos profissionais e acadêmicos quanto ao papel das superfícies ambientais e das mãos como principais reservatórios para disseminação das bactérias resistentes a múltiplas drogas é alarmante; o que implica na possível exposição a tais fatores sem as devidas precauções e, consequentemente, a riscos de contaminação e de disseminação desses patógenos ${ }^{24}$.

A limpeza e desinfecção dos estetoscópios são feitas predominantemente pelos profissionais da área de saúde, na qual foi observada uma prática em 57,14\% dos enfermeiros, $20 \%$ dos fisioterapeutas e $26,27 \%$ dos médicos. O grupo dos acadêmicos são os que menos realizam a limpeza e desinfecção do instrumento, sendo relatado que apenas $10 \%$ os realizam. Isso pode ser explicado devido ao baixo incentivo à realização desta prática e ao baixo conhecimento do potencial do aparelho em ser um vetor de transmissão de infecção hospitalar por esses agentes. Além disso, verifica-se de modo geral uma baixa inclusão da desinfecção destes instrumentos nas estratégias de controles de infecção hospitalares pelos órgãos competentes.

\section{Conclusão}

O estudo conclui que há uma baixa prevalência de microrganismos Gram negativos nas amostras analisadas, correspondendo a $14 \%$. Além disso, o presente estudo observou que apesar da lavagem das mãos durante o expediente de trabalho ser uma prática presente em todos entrevistados, a frequência e a maneira utilizada não são eficazes. Em relação a limpeza e desinfecção dos estetoscópios, registrou-se baixa adesão e prática inadequada principalmente entre os acadêmicos. Portanto, destaca-se a importância do incentivo e orientação relativos às práticas de higienização das mãos e do estetoscópio, criando-se estratégias que atuem na formação acadêmica e na prática cotidiana dos profissionais da saúde, objetivando a redução do número de infecções hospitalares.

\section{Referências}

1. Dutra LGB; Neto HBN, Nedel FB, Lobo EA. Prevalência de contaminação bacteriana em estetoscópios. Rev Inst Adolfo Lutz. 2013; 72(2):155-60. DOI: 10.18241/007398552013721557 
2. Allegranzi B, Bagheri Nejad S, Combescure C, Graafmans $\mathrm{W}$, Attar H, Donaldson L, et al. Burden of endemic health-care-associated infection in developing countries: systematic review and meta-analysis. Lancet. 2011; 377:228-241. DOI:10.1016 / S0140-6736 (10) 61458-4

3. Siegel JD, Rhinehart E, Jackson M, Chiarello L, Health Care Infection Control Practices Advisory Committee. 2007 Guideline for Isolation Precautions: Preventing Transmission of Infectious Agents in Health Care Settings. Am J Infect Control [Internet]. 2007 Dec [cited 2017 Mar 16];35(10):S65-164. Available from: http:// www.ncbi.nlm.nih.gov/pubmed/18068815

4. Jones JS, Hoerle D, Riekse R. Stethoscopes: a potential vector of infection? Ann Emerg Med. 1995; 26(3):296299. DOI: https://doi.org/10.1016/S0196-0644(95)700757.

5. Tatiana Herrera Alvarado JF, Ávila-Agüero ML. Estetoscopios:fuente potencial de infección nosocomial. Acta Pediátrica Costarric. 2005; 19(1)

6. Williams C, Daves DL. Sobrevivência de Staphylococcus aureus resistente a meticilina. Clin Lab Sci. 2009;22(1):34.

7. Whittington AM, Whitlow G, Hewson D, Thomas C, Brett SJ. Bacterial contamination of stethoscopes on the intensive care unit. Anaesthesia. 2009;64(6):620-4. DOI: 10.1111 / j.1365-2044.2009.05892.x.

8. Cristina De Oliveira A, Gonzaga C, Costa R, Souza Damaceno Q, Garbaccio JL. Desafios e perspectivas para a contenção da resistência bacteriana na óptica dos profissionais da saúde. Artig Orig Rev Eletr Enf.;15(3):747-54. DOI: 10.5216/ree.v15i3.19821.

9. Longtin Y, Schneider A, Tschopp C, Renzi G, GayetAgeron A, Schrenzel J, et al. Contamination of stethoscopes and physicians' hands after a physical examination. Mayo Clin Proc. 2014;89(3):291-9. DOI: http://dx.doi.org/10.1016/j.mayocp.2013.11.016

10. Boyce JM. Environmental contamination makes an important contribution to hospital infection. J Hosp Infect. 2007;65:50-4. DOI: 10.1016 / S0195-6701 (07) 60015-2

11. Ferreira AM, Barcelos LS, Rigotti MA, Andrade D, Andreotti JT, Almeida MG. Integrative Review Article Areas of Hospital Environment: a Possible Underestimated Microbes Reservoir? J Nursing. 2013;7(5). DOI: https://doi.org/10.5205/1981-8963v7i5a11646p4171-4182-2013

12. Ferreira AM, Andrade D de, Rigotti MA, Ferreira MVF. Condition of cleanliness of surfaces close to patients in an intensive care unit. Rev Lat Am Enfermagem. 2011;19(3):557-64. DOI: http://dx.doi.org/10.1590/ S0104-11692011000300015

13. Ferreira AM, Andrade D de, Rigotti MA, Almeida MTG de. Methicillin-resistant Staphylococcus aureus on surfaces of an Intensive Care Unit. Acta Paul Enferm. 2011;24(4):453-8. DOI: http://dx.doi.org/10.1590/ S0103-21002011000400002
14. Wenzel RP. The economics of nosocomial infections. J Hosp Infect. 1995;31(2):79-87. DOI: https://doi. org/10.1016/0195-6701(95)90162-0.

15. Brasil. Segurança do paciente em serviços de saúde: limpeza e desinfecção de superfícies [Internet]. 1st ed. Agência Nacional de Vigilância Sanitária, editor. Brasília; 2012 [cited 2017 Mar 16]. Available from: http:// www20.anvisa.gov.br/segurancadopaciente/index.php/ publicacoes/item/seguranca-do-paciente-em-servicosde-saude-limpeza-e-desinfeccao-de-superficies

16. Oliveira AC de, Damasceno QS. Superfícies do ambiente hospitalar como possíveis reservatórios de bactérias resistentes: uma revisão. Rev da Esc Enferm da USP. 2010;44(4):1118-23. DOI: http://dx.doi.org/10.1590/ S0080-62342010000400038

17. Warye KL, Murphy DM. Targeting zero health care associated infections. Am J Infect Control. 2008;36(10):683-4. DOI: 10.1016 / j.ajic.2008.10.016

18. World Health Organization. WHO guidelines on hand hygiene in health care : first global patient safety challenge: clean care is safer care. [Internet]. World Health Organization, Patient Safety; 2009 [cited 2017 Mar 16]. 262 p. Available from: http://www.who.int/ gpsc/5may/tools/9789241597906/en/

19. Xavier MS, Ueno M. Contaminação bacteriana de estetoscópios das unidades de pediatria em um hospital universitário Bacterial contamination of stethoscopes in pediatric units at a university hospital. Rev Soc Bras Med Trop. 2009;42(2):217-8. DOI: http://dx.doi.org/10.1590/ S0037-86822009000200026

20. Santos GE de O. Cálculo amostral: calculadora online [Internet]. [cited 2017 Oct 4]. Available from: http:// www.calculoamostral.vai.la

21. Callegari-Jacques S. Bioestatística. Princípios e Aplicações. Porto Alegre: Artmed; 2006.

22. Zar JH. Biostatistical Analysis [Internet]. 3rd ed. USA: Pearson; 1996 [cited 2017 Sep 23]. Available from: https://www.pearson.com/us/higher-education/ program/Zar-Biostatistical-Analysis-3rd-Edition/ PGM322881.html

23. Héctor A. Baptista-González; Clara Aurora ZamoranoJiménez. Estetoscopio, bata y corbata, y el riesgo de infecciones nosocomiales. Noticias Médicas Y Perspectivas; Rev Invest Med Sur Mex, 2011; 18 (4): 195202

24. Sales VM; Oliveira E; Célia R; Gonçalves FR; Melo CC. Análise microbiológica de superfícies inanimadas de uma Unidade de Terapia Intensiva e a segurança do paciente. Rev Enf Ref. 2014; 3. DOI: http://dx.doi.org/10.12707/ RIII1293 
Anexo 1: Questionário modificado pelos autores que foi aplicado aos profissionais de saúde e acadêmicos de um hospital escola de Presidente Prudente.

\section{QUESTIONÁRIOSOBRE LIMPEZAE DESINFECÇÃO DAS MÃOS E ESTETOSCÓPIOS}

PROFISSÃO: ALAHOSPITALAR

1) Você costuma limpar e desinfetar seu(s) estetoscópio(s)? !) SIM ( ) NÃo

2) Qual a frequência? () após cada paciente; ( ) diariamente; ( ) semanalmente; (.) mensalmente; ( ) outra, qual?

3) Quando foi a última vez que realizou a higienização no(s) estetoscópio(s)?

4) 0 que costuma usar para limpar e desinfetar o(s) estetoscópio(5)? Ex: Água

5) Você já recebeu em algumas ocasião informações ou incentivo sobre a limpeza dos. estetoscópio(s)? () SIM ( ) NÃO ( ) REGULARMENTE ( ) NÃORECORDA

6) Você costuma lavar as mãos durante o expediente de trabalho? () SIM ( ) NÃO

7) Qual a frequência?

8) Já se esqueceu de lavar as mãos alguma vez para atender a um paciente? () SIM ( ) NÃ̃

9) Já recebeu em alguma ocasião informações ou incentivo sobre a higienização das mãos? ()) SIM ( ) NÃO ( ) REGULARMENTE ( ) NÃORECORDA

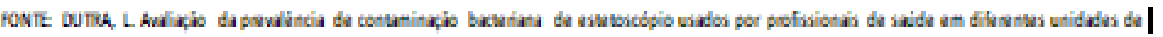

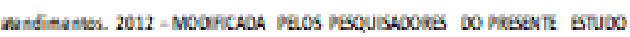

Como citar este artigo:

Coradini MHS, Neto NPS, Magnesis LG, Melo CF, Almeida MC, Zago SCS. Identificação da prevalência de bactérias gram negativas em estetoscópios e a prática da higienização por profissionais da saúde em um hospital do oeste paulista. Rev. Aten. Saúde. 2019;17(59):75-82. 